\title{
SOSIALISASI E-COMMERCE UNTUK USAHA MIKRO KECIL DAN MENENGAH (UMKM) DI RW 18 KELURAHAN TEMBESI KECAMATAN SAGULUNG
}

\author{
E-COMMERCE SOCIALIZATION FOR MICRO SMALL AND MEDIUM \\ ENTERPRISES (UMKM) IN RW 18 KELURAHAN TEMBESI KECAMATAN \\ SAGULUNG
}

\author{
Seftia Azrianti \\ Program Studi Ilmu Hukum, Fakultas Hukum, Universitas Riau Kepulauan \\ s_azrianti@yahoo.co.id
}

\begin{abstract}
Abstrak
Penyelenggaraan sosialisasi dan penerapan e-commerce ini dilakukan untuk membantu meningkatkan hasil penjualan mitra. Berdasarkan hasil survey lapangan di Perumahan Permata Rhabayu terdapat 7 Usaha Mikro Kecil dan Menengah (UMKM) yang bergerak pada bidang menjahit pakaian, produksi makanan kue, kerupuk, dan servis elektronik. Hampir 80 persennya mengalami kendala dalam pemasaran produk dan jasa mereka, diamana hasil penjualan tidak maksimal karena metode pemasaran yang sangat terbatas. Metode kegiatan yang digunakan adalah dengan menggunakan pengamatan langsung serta melakukan pendekatan kepada para pelaku usaha dan melakukan praktek penerapan pemasaran produk melalui e-commerce. Kegiatan e-commerce ini berhasil dilakukan dengan baik, hal ini dibuktikan dengan telah dibuatnya berbagai jenis media sosial kepada para UMKM baik dalam bentuk whatsapp, instagram, facebook dan lain-lain sebagai media promosi produk usaha meraka. Sehingga usaha mereka sudah dikenal luas dan tentunya meningkatkan permintaan.
\end{abstract}

Kata Kunci: Sosialisasi, E-Commerce, UMKM

\begin{abstract}
This socialization and application of e-commerce is carried out to help increase partner sales results. Based on the results of a field survey at Permata Rhabayu Housing, there are 7 Micro, Small and Medium Enterprises (UMKM) which are engaged in sewing clothes, producing pastries, crackers, and electronic services. Almost 80 percent of them experience problems in marketing their products and services, where the sales results are not optimal because of very limited marketing methods. The method of activity used is by using direct observation and approaching business actors and implementing product marketing practices through e-commerce. This ecommerce activity is successfully carried out, this is evidenced by the creation of various types of social media for MSMEs in the form of WhatsApp, Instagram, Facebook and others as a medium for promoting their business products. So that their business is widely known and of course increases demand.
\end{abstract}

Keyword: Sosialiasation, E-Commerce, UMKM,

\section{PENDAHULUAN}

Secara umum usaha kecil di perumahan memiliki kendala dalam pemasaran produk dan jasa. Biasanya pemasaran produk dan jasa pda usaha perumahan dilakukan dengan cara konvensional, dan tidak mengunakan teknologi informasi. Saat ini teknologi informasi berkembang dengan pesat diantaranya berbagai media sosial. Keberadaan media sosial yang menjamur pengunaannya ditengah masyarakat dapat di gunakan menjadi media promosi dan penjualan berbasis informasi teknologi, salahsatunya disebut dengan e-commerce. 
Menurut Suyanto (2003) mendefinisikan e-commerce sebagai konsep baru yang bisa digambarkan sebagai proses jual beli barang atau jasa pada internet. Turban et al., (2008) mengatakan e-commerce merupakan jual beli atau pertukaran produk, jasa dan informasi melalui jaringan informasi termasuk internet. Sedangkan menurut Karmawan (2010) $e$ commerce adalah suatu jenis dari mekanisme bisnis secara elektronik yang memfokuskan diri pada transaksi bisnis berbasis individu dengan menggunakan internet (teknologi berbasis jaringan digital) sebagai medium pertukaran barang atau jasa baik antara dua buah institusi (business to business) dan konsumen langsung (business to consumer), melewati kendala ruang dan waktu yang selama ini merupakan hal-hal yang dominan. Dengan aplikasi ecommerce, hubungan antar perusahaan dengan entitas eksternal lainnya (pemasok, distributor, rekanan, konsumen) dapat dilakukan secara lebih cepat, lebih intensif, dan lebih murah daripada aplikasi prinsip manajemen secara konvensional (door to door, one-to-one relationship).

Usaha yang dimiliki masyarakat di Perumahan Permata Rhabayu RW 18 secara keseluruhan tergolong kedalam Usaha Mikro Kecil dan Menengah (UMKM) menurut Undang-Undang Nomor 20 Tahun 2008. Usaha Mikro adalah usaha produktif milik orang perorangan dan/atau badan usaha perorangan yang memenuhi kriteria sesuai peraturan perundang-ndangan yang berlaku. Usaha Kecil adalah usaha ekonomi produktif yang berdiri sendiri, yang dilakukan oleh orang perorangan atau badan usaha yang bukan merupakan anak perusahaan atau bukan cabang perusahaan yang dimiliki, dikuasai, atau menjadi bagian baik langsung maupun tidak langsung dari Usaha Menengah atau Usaha Besar yang memenuhi kriteria Usaha Kecil sebagaimana dimaksud sesuai dengan peraturan perundang-undnagan berkaitan dengan UMKM kemudian, Usaha Menengah adalah usaha ekonomi produktif yang berdiri sendiri, yang dilakukan oleh orang perorangan atau badan usaha yang bukan merupakan anak perusahaan atau cabang perusahaan yang dimiliki, dikuasai, atau menjadi bagian baik langsung maupun tidak langsung dengan Usaha Kecil atau Usaha Besar dengan jumlah kekayaan bersih atau hasil penjualan tahunan.

Usaha kecil di Perumahan Permata Rhabayu memiliki kendala pemasaran hasil produksi. Strategi pemilik usaha dalam memasarkan hasil produksinya dirasa kurang maksimal, terutama sekali dalam pemasaran dan pengenalan produk atau jasa yang dihasilkan, sehingga produk dan jasa UMKM tersebut hanya dikenal dan digunakan di 
seputaran Perumahan Permata Rhabayu saja. Oleh sebab itu, pengabdi melakukan sosialisai dan penerapan e-commerce untuk membantu dan mengajarkan serta memberi masukan kepada setiap UMKM yang ada di Perumahan Permata Rhabayu dengan harapan dapat membantu memajukan kegiatan usaha yang dilakukan dan lebih dikenal di kalangan masyarakat yang lebih luas.

\section{METODOLOGI}

Kegiatan ini dilakukan pada bulan bulan Desember 2019 di perumahan Permata Rhabayu RW 18, Kelurahan Tembesi, Kecamatan Sagulung Kota Batam. Pendekatan pelaksanaan kegiatan yang digunakan adalah dengan menggunakan observasi dan pengamatan langsung serta melakukan pendekatan kepada para pelaku usaha dan melakukan praktek penerapan pemasaran produk melalui e-commerce.

Tahapan pelaksanaan kegiatan sosialisasi dan penerapan e-commerce ini terdiri dari beberapa tahapan, yaitu:

a. Observasi atau Pengamatan. Observasi atau pengamatan dilakukan terhadap setiap kegiatan usaha di perumahan Permata Rhabayu untuk memastikan mitra kegiatan pengabdian ini tepat sasaran.

b. Wawancara kepada pemilik/pelaku usaha di lokasi kegiatan pengabdian, untuk menentukan kendala utama yang dihadapi khsusnya pada bidang pemasaran produk dan jasa.

c. Memberikan sosialisai dan penerapan e-commerce serta praktek pemasaran produk dan jasa berbasis elektonik media sosial.

d. Evaluasi dilakukan setelah beberapa minggu untuk melihat adanya kenaikan penjualan dari peserta mitra.

\section{PEMBAHASAN}

Berdasarkan hasil survey lapangan di Perumahan Permata Rhabayu terdapat 7 Usaha Mikro Kecil dan Menengah (UMKM) yang bergerak pada bidang menjahit pakaian, produksi makanan kue, kerupuk, dan servis elektronik. Hampir 80 persennya mengalami kendala dalam pemasaran produk dan jasa mereka, diamana hasil penjualan tidak maksimal karena metode pemasaran yang sangat terbatas. 
Tabel 1. Daftar Pelaku dan Jenis Usaha UMKM di Perumahan Permata Rhabayu

\begin{tabular}{clll}
\hline No & \multicolumn{1}{c}{ Nama } & \multicolumn{1}{c}{ Alamat } & \multicolumn{1}{c}{ Jenis Usaha } \\
\hline 1 & Bima Taylor & Blok FF No. 25 & Menjahit Baju \\
2 & Happy Service & Blok DD No.8 & Service Elektronik \\
3 & Tinakadim Cake and Snack & Blok F No 3 & Usaha Kue \\
4 & Bu Diswar Peyek & Blok H No 3 & Usaha Kerupuk \\
5 & Bu Dian Kue AKar Kelapa & Blok E No 4 & Usaha Kue Akar Kelapa \\
6 & Bu Erti Kue Bawang & Blok E No 7 & Usaha Kue Bawang \\
7 & Bu Salimah Kue Keju Tajin & Blok H No. 8 & Usaha Kue Keju \\
\hline
\end{tabular}

Sumber : Hasil Survey di Perumahan Permata Rhabayu Tahun 2019

Pertumbuhan penggunan internet yang berkembang dengan pesat seharusnya menjadi alasan mengapa kegiatan usaha harus mencoba menerapkan e-commerce pada masyarakat. Walaupun memang perkembangan pengguna e-commerce belum begitu mengesankan dibandingkan dengan pertumbuhan pengguna internet. Fenomena e-commerce belum dapat dipahami dan didukung dengan baik terutama di negara berkembang seperti Indonesia, begitu juga di Kota Batam, khususnya di lingkungan perumahan Permata Rhabayu dan sekitarnya. Konsumen masih belum memiliki kepercayaan terhadap keamanan bertransaksi, kesamaan produk yang ditampilkan dengan kenyataannya, sampai dengan konsumen yang memang belum memiliki kemampuan untuk itu.

Dengan adanya internet proses pemasaran dan penjualan dapat dilakukan kapan saja tanpa terikat ruang dan waktu. Salah satupenerapan internet dalam bidang bisnis dan perdagangan adalah electroniccommerce (e-commerce). Usaha Kecil dan Menengah (UKM) merupakan kelompok pelaku ekonomiterbesar dalam perekonomian Indonesia dan menjadi dinamisator pertumbuhanekonomi pasca krisis ekonomi (Nuryanti, 2013).

Penerapan e-commerce akan dapat meningkatkan keunggulan bersaing dari perusahaan. Implementasi dari e-commerce membutuhkan strategi matang yang telah diputuskan oleh manajemen dari perusahaan, diantaranya mempersiapkan sumber saya perangkat teknologi dan sumber daya manusia yang handal dalam bidang teknologi informasi. Membangun sistem informasi untuk mengelola operasional perusahaan. Memiliki mekanisme pelayanan dan transaksi yang cepat dan singkat dengan keamanan yang baik. Menjalin kerja sama yang baik dengan para supplier dan distributor. Jika semua hal diatas dapat dilakukan dengan baik akan dapat meningkatkan keunggulan bersaing yang dimiliki perusahaan. Hal tersebut lah yang ingin kami bagikan untuk membantu kegiatan UMKM yang ada di Perumahan Permata 
Rhabayu. Dengan demikian diharapkan ilmu dan kemampuan tersebut dapat membantu warga yang mempunyai kegiatan UMKM.

Sebagai mana di sampaikan Jauhari (2012) bahwa untuk meningkatkan daya saing UKM serta untuk mendapatkan peluang ekspor dan peluang bisnis lainnya dapat dilakukan dengan memanfaatkan perkembangan Information and Communication Technology (ICT), utamanya ecommerce. Tidak hanya memanfaatkan internet sebagai alat untuk melakukan promosi atau mencari peluang bisnis, tetapi juga harus diimbangi dengan pengelolaan administrasi yang baik melalui penggunaan software yang tepat. Sebagai upaya mengembangkan bisnis, banyak hal yang perlu dilakukan, salah satunya adalah dengan menerapkannya sistem e-commerse. E-commerse dalam dunia usaha adalah penggunaan tekhnologi terkini seperti internet dalam memudahkan kegiatan-kegiatan bisnis. Melalui internet pelaku usaha dapat dengan mudah berkomunikasi dan surat menyurat melalui email, chating, dan lain sebagainya. Dapat mempromosikan produk melalui iklan online, juga dapat memperkenalkan perusahaan dan mencari pelanggan baru melalui laman (website) (Maryama, 2013).

Setelah melihat kondisi UMKM di daerah Perumahan Permata Rhabayu dengan melakukan pengamatan terlebih dahulu dan selanjutnya melakukan wawancara secara intensif terhadap pemilik usaha UMKM di lokasi kegiatan pengabdian. Terdapat beberapa kegiatan UMKM di Perumahan Permata Rhabayu, seperti jasa Servis Elektronik, Jasa Menjahit, dan Produk Kue. Sosialisasi dan pengajaran e-commerce yang dilakukan berjalan dengan baik dan lancar, dan penuh sambutan dan dukungan dari ketua RW dan warga Perumahan Permata Rhabayu.
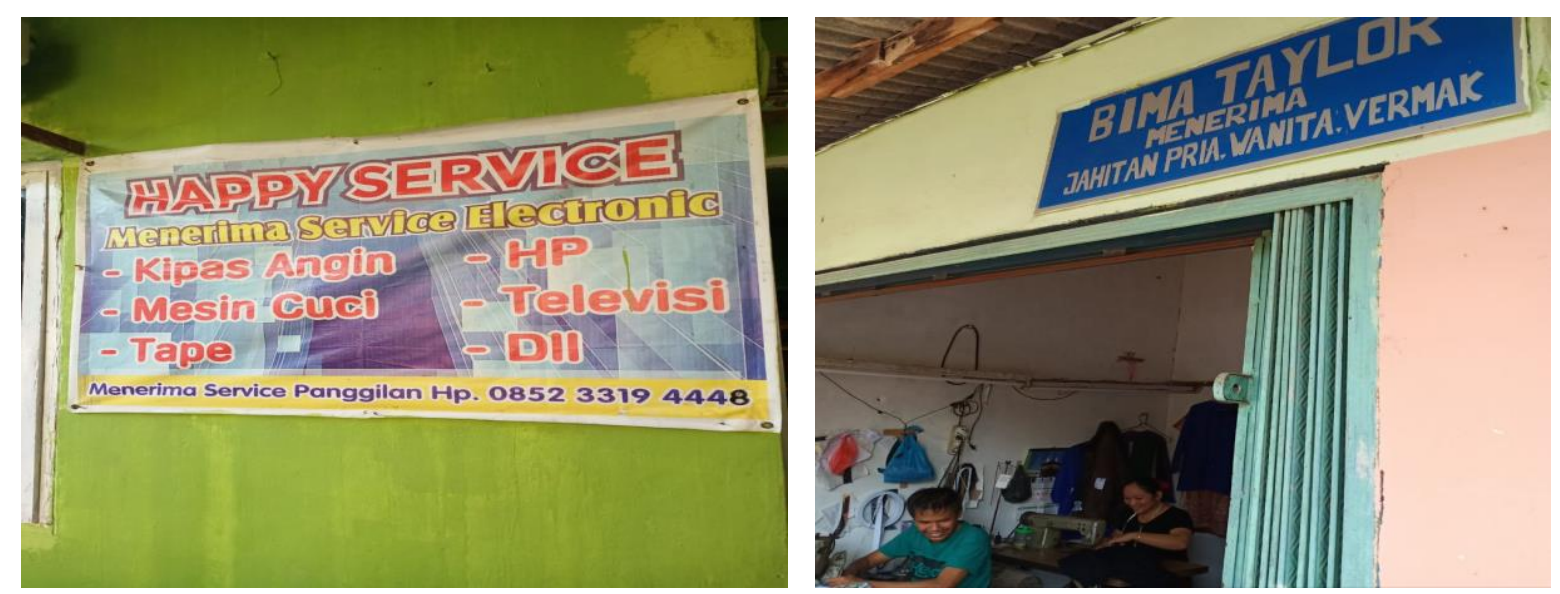

Figur 1. Usaha Kecil di Perumahan Permata Rhabayu 
Kami mengunjungi tempat usaha masing-masing (yang di area RW 18) dan mengajarkan bagaimana menjadikan teknologi menjadi alat pemasaran produk dan jasa yang dimiliki, membuatkan akun sosial media (instagram) untuk para warga yang memiliki kegiatan UMKM dan bagaimana cara menggunakannya. Langkah yang dilakukan terkait dengan penggunaan media sosial sebagai cara untuk memasarkan hasil produk adalah dengan membantu membuatkan akun untuk para pelaku usaha UMKM dimulai dari akun facebook, instagram. Kemudian membantu meng upload gambar usaha mereka dimasing masing akun pribadinya. Kemudian membantu mereka menyebarkan gambar yang di upload tersebut ke grup-grup jual beli yang ada di laman facebook dan instagram.

Kegiatan e-commerce ini berhasil dilakukan dengan baik, hal ini dibuktikan dengan sudah dibuatnya berbagai jenis media sossial kepada para UMKM baik dalam bentuk whatsapp, instagram, facebook dan lain-lain. Sehingga usaha mereka sudah dikenal luas dan tentunya meningkatkan permintaan akan produk penjualan. Seperti usaha kue bawang sebelum meggunakan akun media sosial sebagai alat bantu dalam pemasaran hanya di produksi sebanyak 50 bungkus perhari setelah di pasarkan melalui akun facebook maka ada permintaan dari daerah diluar Perumahan Permata Rhabayu dengan pengantaran menggunakan jasa kurir dan produksinya bertambah hingga menjadi 100 bungkus perhari.

Dengan demikian telah tercapai hasil yang memuaskan, untuk membantu mengembangkan perekonomian masyarakat, dan berharap apa yang telah sosialisasikan dan ajarkan dapat berguna bagi warga dan dapat dikembangkan dari waktu ke waktu.

\section{KESIMPULAN DAN SARAN}

Sosialisasi dan pengajaran e-commerce yang dilakukan berjalan dengan baik dan lancar, dan penuh sambutan dan dukungan dari ketua RW dan warga Perumahan Permata Rhabayu. Banyak hal yang kami lalui dan kami hadapi dalam melakukan pendekatan dan pengenalan dengan warga Perumahan Permata Rhabayu. Dengan mempelajari tiap karakter warga dan melihat apa yang dapat kami bantu di Perumahan Permata Rhabayu dengan bekal pengetahuan yang kami miliki. Dengan menggunakan e-commerce maka kegiatan UMKM dapat lebih efisien dan efektif dalam meningkatkan keuntungannya.

Diharapkan dengan pengajaran yang kami lakukan dan kami sosialisasikan dapat mengembangkan perekonomian di Perumahan Permata Rhabayu. Karena tujuan utama kami 
dalam melakukan sosialisasi ini adalah untuk memberdayakan masyarakat urban, mebantu meningkatkan perekonomian masyarakat dan mengembangkan kegiatan UMKM yang ada di Perumahan Permata Rhabayu dan para pelaku usaha bisa memanfaatkan dan mengoptimalkan akun media sosial yang telah diajarkan dengan baik .

\section{REFERENSI}

Jauhari, J. (2012). Studi Pendahuluan Untuk Pengembangan Model Pemasaran dan Penjualan Produk Usaha Kecil dan Menengah (UKM) Berbasis E-Commerce di Propinsi Sumatra Selatan. Makalah. Fakultas Ilmu Komputer, Universitas Sriwijaya. 15 hlm.

Karmawan, I.G.M., Sundjaja, A.M., dan Luhukay, D. 2010. Analisis Dan Perancangan ECommerce Pd. Garuda Jaya. Makalah disampaikan pada Seminar Nasional Aplikasi Teknologi Informasi (SNATI), pp. 17-22B Yogyakarta, 19 Juni 2010.

Maryama, S. (2013). Penerapan E-Commerce Dalam Meningkatkan Daya Saing Usaha. Jurnal Liquidit, 2(1), 73-79.

Nuryanti (2013). Peran E-commerce untuk Meningkatkan Daya Saing Usaha Kecil dan Menengah ( UKM ). Jurnal Ekonomi, 21(4), 1-15.

Suyanto, M., (2003). Strategi Periklanan pada E- Commerce Perusahaan Top Dunia, Yogyakarta; Penerbit Andi. 265 hlm.

Turban, E., King,D., Mckay, J., Marshall, P., Lee, J.K dan Viehland, D. (2008). Electronic Commerce: A Managerial Perspective. Pearson Education, New Jersey. $520 \mathrm{p}$

Undang-Undang Nomor 20 Tahun 2008. Tentang Usaha Mikro, Kecil, dan Menengah. Menteri Hukum dan Hak Asasi Manusia. Jakarta. 